\title{
Analysis on Suning Commerce Group's Problem and Its Solution Based on Big
}

Data

\author{
Jianhua Zhang, Jia Ran*, and Dapeng Dong \\ Management Engineering Department, Zhengzhou University, Henan province, China \\ 969480705@qq.com,996934418@qq.com
}

Keywords: Big data, Suning Commerce Group, Online to Offline E-commerce

\begin{abstract}
In recent years, the big data development has obtained amazing achievement. Big data has permeatedall walks of life. In face of strong competitors like Taobao and Jingdong, (predecessor was Suning Appliance), Suning should draw support from big data's strength to contribute themselves to carrying out transformation. This paper studies present development situation of Suning Corporation Group, and discoveries its business existence question, then uses the unique idea, the technical method and the infrastructure in the age of big data, providing some solutions to these questions, to help Suning Commerce Group walk more quickly and more steadily on the road of reformation, and realize the enterprise prospect well, then provide a higher quality service for the user.
\end{abstract}

\section{INTRODUCTION}

September 5, 2015 The State Council issued "Promotes Big Data Development Motion Summary” (to hereafter refer to as "Summary"). "Summary" outlined our country big data development application prospect in the next 5 to 10 years, and symbolized our national big data development entered the brand-new stage (Zhiguang Shan,2015). As big as national strategy, as slightly as daily life, many enterprises drew support from big data, particularly in the field of e-commerce, which is based on Internet and information technology. The influence which the big data produced is more and more widespread. Suning already saw this tendency, on Month 2, 2013. Suning changes his name as "Suning Commerce Group”, which full name is Suning Commerce Group CO., LTD. Suning opened the cloud business platform on December 9, 2013. Suning Silicon Valley Institute, committing to big data, internet finance and other cutting-edge areas, opened on November 19, 2013. The blustery big data time has brought opportunity and challenge for Suning.

\section{THE CONNOTATION AND CH-ARACTERISTIC OF BIG DATA}

"The big data" comes from the futurologist to hold the husband forces "Third Tide" most early. "The big data” became profession popular glossary in the Internet technology only from 2009years, but its concept still did not have an accurate definition at present. The McKinsey says "big data is a collection of data that can't be crawled, managed, and processed with traditional database software tools for a certain period of time." Wikipedia argues that "big data is meant that it can ' $t$ be used for a certain period of time with regular software tools its content to crawl, manage and process the data set” (Yong Zhao, Hui Lin, Yushi Shen, 2014).

There are wide divided opinions at present about the big data definition expression, but its " $4 \mathrm{v}$ " feature is recognized by the majority of scholars. First, Volume: large volume. From GB to TB to PB, the amount of big data is growing exponentially. Second, Velocity: fast. Real-time data creating enable big data with the ability to deal with problems quickly. Third, Variety: more types. Big data has a large number of structured and unstructured data, such as text, images and data from sensor and so on. Fourth, Value: high value. The value density of unit data in big data is decreasing, but the overall value is increasing, which contains great commercial value, which is regarded as "oil and gold" in business (Yong Zhao, Hui Lin, Yushi Shen, 2014).

Therefore, it can be considered that the big data is essentially a comprehensive, mixed and has a large amount of data, input and processing speed, data diversity, low density and other characteristics of the data set.

\section{SUNING COMMERCE GROUP DEVELOPMENT STATUS AND PROBLEMS}

\subsection{Suning development overview}

February 2013 Suning Appliance changed its name to Suning Commerce Group, from the traditional retail business transformation for the $\mathrm{O} 2 \mathrm{O}$ "e-commerce" pattern. $\mathrm{O} 2 \mathrm{O}$ (online to offline) pattern called online purchase offline consumption patterns. Consumers buy products online, and enjoy the service to offline under entity shop (Dongrui Bai, Yunkang Yue,2013). Suning's new e-commerce pattern includes "electronic business +shop business + retail service providers" three parts, "shop business" refers to the traditional physical stores, “electronic business” is Suning's e-commerce platform, including Suning purchase, Redbaby that was acquired by Suning, and Bring fun network and other business enterprises. "Retail service providers" is a retail service system established by Suning over past 20 years. As a leader in the retail industry, Suning implements online and offline linkage, providing users with high-quality 
one-stop service, gaining good corporate reputation, but his road of reform is by no means problem-free. Suning operating income of 2013 year was 105.292 billion, an increase of $7.19 \%$ over 2012, but the profit has dropped significantly from 1.343 billion in 2012 down to 1.458 billion in 2014, after deducting non-recurring gains and losses to 1.252 billion. The data show that Suning's transformation is not successful, in addition to the traditional retail environment is not optimistic reasons, Suning itself also need some time to adapt to the strategic transformation brought about by a series of changes.

Table 1: Suning Commerce Group 2013 to 2016 part of the financial data

\begin{tabular}{lllll}
\hline & $\begin{array}{l}\text { Business } \\
\text { income }\end{array}$ & $\begin{array}{l}\text { Business } \\
\text { income } \\
\text { wave }\end{array}$ & Net profit & $\begin{array}{l}\text { Net profit } \\
\text { wave }\end{array}$ \\
\hline 2013 & $105,292,229$ & $/$ & 306,725 & $/$ \\
2014 & $108,925,296$ & $3.45 \%$ & $-1,252,211$ & $-508.25 \%$ \\
2015 & $135,547,633$ & $24.44 \%$ & $-1,464,864$ & $-16.98 \%$ \\
2016 & $148,585,331$ & $9.62 \%$ & $-1,107,612$ & $24.39 \%$ \\
\hline
\end{tabular}

\subsection{Suning commerce group problems}

Through the study of the operating conditions of Suning Commerce Group in recent years, it is found that the main problems of Suning Commerce Group are concentrated in the four aspects, including electricity business platform, logistics management, commodity price and organizational structure.

First, the electricity business platform

China's electronic commerce domain competition is intense. The traditional retail trade march electronic commerce domain can't be blind, and should wait for an appropriate opportunity. Suning as a traditional retail business, the time of stepping into the field of e-commerce is short, lacking of e-commerce operating experience. No matter is the front end user interface or the backstage technical support, Suning does insufficiently well. Compared with Taobao and Jingdong, Suning has no stable traffic and a large customer base, and mainly relies on advertising and low prices to attract customers, and has not established good stable relations with customers, which is clearly not a long-term plan.

Second, the logistics management

Logistics is an extremely important part of the process of e-commerce. Suning's slogan is "stores become online shopping delivery point", but the implementation of this slogan is not in-depth. First Suning logistics center location is not reasonable, no combination with distribution costs, distribution efficiency and other practical factors, while the lack of professional logistics management and technical personnel, leading to customer satisfaction is not high, the overall impression of Suning greatly reduced (Wenli Luo,2013).

Third, the commodity price

Suning launched the "two-line with the same price" strategy, but the operating costs of offline stores far higher than online, greatly reducing the Suning store profit margins. And many brands have their own pricing system, refusing to accept Suning's "two-line with the same price” strategy, in March 2014 Gree withdrawal from Suning is a typical example (Feng Wu, 2014).

Fourth, the organizational structure

Suning has 180,000 office clerks, but its business situation is far less than just tens of thousands of employees Taobao and Jingdong. Enterprises under internet environment should pursue the organization of flat and streamlined staff. Suning staff redundancy, internal wastage is serious, hindering their development.

\section{SUNING COMMERCE GROUP PROBLEM SOLVING STRATG- IES ON BIG DATA}

Conforming to the background of big data age, discuss four aspect questions and propose the following solution strategy in view of Suning Commerce Group:

First, strengthen the platform construction, develop marketing programs.

First of all, the e-commerce platform is a business name card of Suning, which shows consumers a window of goods. Suning should learn excellent experience from outstanding business enterprises. Suning only makes perfect first impression to the customer, can obtain customer's favour and trust. Suning can use the transaction data and evaluation information to establish a model of selecting comments, to exclude these comments that has no reference value to the people, such as brush and malicious bad feedback, so that customers enhance the business platform for the goodwill and trust (Xiaozhou Wang, 2015).

Then, Suning adhere to the whole category of development strategy now, but in the face of Taobao and Jingdong such strong competitors, Suning should "specialize in strengths". Consolidate position in electrical appliance field first, acquiring market share, and then extend his power to other areas. Pursuing "small and fine" first, and then pursuing "big and complete", rather than expand blindly in the situation which technology and service all consummate insufficiently. At the same time, in addition to "two-line with the same price” strategy, Suning should transform marketing methods to promote the customer current capacity of website. Jingdong precision marketing in big data environment is a good example. Through browse record, purchase record and pays record, Suning can forecast consumer's purchase tendency, and push a pair of information for them (Shouqiang Sun, Bin Huang, Juan Liao, 2017). Suning should use big data to meet individual and different consumer demand (Tianwen Wang, 2017).

Second, improve the logistics management, improve delivery quality.

In the beginning of transformation, Suning devoted a lot of money to the warehouse construction, vehicle configuration and other aspects, but in the era of large data, just put the capital is not enough, more importantly, the use of technical means to reform the logistics pattern, reduce logistics costs and improve logistics efficiency. Suning can use the optimization algorithm of big data to plan the location of the logistics center, optimize the transport routes. Make use of statistical analysis arithmetic in the era of big data to build more reasonable layout of warehouses (Tianwen Wang, 2017). Suning 
self-built logistics has a certain competitive advantage, and on this basis Suning should improve the quality of the logistics system staff, in particular, to improve the delivery staff attitude and work ability to enhance their reputation.

Third, postpone the two lines with the same price, perfect price system.

Two-line same price is on behalf of that $\mathrm{O} 2 \mathrm{O}$ pattern has developed into the mature stage condition. It is too early for Suning, who is in the beginning of reforming, to implements the same price strategy. Many brands prices are different between online and offline, and different regional prices are different, too. It will inevitably lead to part of supplier's dissatisfaction because Suning want to break the price mechanism violently that suppliers have established for many years. Suning should give themselves and suppliers a transition period, implementing the variation fixed price strategy first, carrying out the same price strategy again after in-line current capacities keeping stable (Xiaowei Lian,2013). Suning can use big data to establish price and sales correlation model, to analyse the impact of commodity pricing on merchandise sales. Suning can first sell the price of low correlation area as the same price strategy pilot area, and then expands the scope of the pilot slowly, finally realizes completely the same price.

Fourth, optimize human resources, streamline organizational structure.

Suning employees up to 180,000 , much higher than other Internet companies, Suning should streamline personnel and simplify the structure firstly. Suning can use big data to establish a matching model to analyse the staffs' work ability, personality and other aspects of the data is matched with the job, the use of large data to establish the work of the staff curve, record the work of the staff to complete the rate of analysis of the staff's ability to work. Predict the career development of employees, tailor-made for the staff of the appropriate training program to achieve the best allocation of human resources (Ying Zhao, 2016).

\section{CONCLUSIONS}

Suning's “cloud business” pattern is very advanced, combined with advantages of traditional business and e-commerce. The internet is used as a trading window, and offline stores become a guarantee of transactions. This pattern not only is the development trend of e-commerce, but also is a perfect state that $\mathrm{O} 2 \mathrm{O}$ electricity business pursuit. But to consider the retail environment, suppliers, distributors and consumers and many other factors, Suning's pattern implements a long way to go. Suning, although riding the retail industry for decades, but in the field of electricity is still a novice. Big data is undoubtedly the cornerstone of Suning reform on the road, so Suning reform has a multiplier effect. Many enterprises to catch a big data express, and achieved good development. Suning should keep up with the trend, seizing the opportunity to make themselves in the fierce competition in the market come to the fore. "Practice makes a true knowledge", also hope Suning can go to the right track soon.

\section{ACKNOWLEDGEMENTS}

This work is supported by the Excellent Young Teacher Development Fund Project of Zhengzhou University (Foundation No.2015 SKYQ15) and the Innovation and Development Fund of Zhengzhou University School of Management Engineering (Foundation No. 20170604).

\section{REFERENCES}

[1] Dongrui, Bai, Yunkang Yue, 2013. Introduction to e-commerce, People's Posts and Telecommunications Press. Beijing, 2nd edition.

[2] Xiaowei Lian, 2013. Double line with same price is not yet mature, Modern appliances. (13), 50-51.

[3] Wenli, Luo, 2013. Suning Commerce Group logistics new solution, China Logistics and Purchasing. (06), 44-66.

[4] Zhiguang, Shan, 2015. The top-level design data of the development of big data in the country Powerhouse's horn horns - Some explanations on the Platform for Action to Promote Big Data Development, Money China. (10), 30-35.

[5] Shouqiang, Sun, Bin, Huang, Juan, Liao, 2017. beginning and realizing precision marketing with an environment of big data, Modern Business. (19), 38-39.

[6] Tianwen Wang, 2017. Application and Practice of Large Data Technology in Jingdong Warehouse - "Big Data and Wisdom Logistics”, Logistics Technology and Application. 22 (05), 148-149.

[7] Xiaozhou, Wang, 2015. Big data for the electricity business platform model innovation, Modern industrial economy and information technology. (13), 84-85.

[8] Feng, Wu, 2014. the strategy of two with same price about Suning Commerce Group, Journal of Wuhan Vocational \& Technical College. (05), 31-35.

[9] Ying, Zhao, 2016. big data under the enterprise human resource management characteristics, China Management Information. 19(06), 130-131.

[10] Yong, Zhao, Hui, Lin, Yushi, Shen, 2014. Big data revolution-theory, model and technological innovation, Electronic Industry Press. Beijing, 1st edition. 